\title{
Pengujian Sistem Pendukung Keputusan Metode Simple Additive Weighting dan Weighted Product dengan Matlab
}

\author{
Alex Rikki \\ STMIK Pelita Nusantara, Jl. Iskandar Muda No. 1 Medan, Sumatera Utara, Indonesia \\ http : // www.penusa.ac.id, Email : alexrikisinaga@gmail.com
}

\begin{abstract}
The concept of a program to assist decision-making is currently developing very rapidly. Many methods are used to assist in the decision making process. One method that can be used to solve the Multi Attribute Decision Making (MADM) problem with the SAW, Weighted Product method and others. This is because the method is simple, easy to understand, computationally efficient and has the ability to measure the relative performance of decision alternatives in a simple mathematical form. The problem is that to solve a particular MADM case it may be difficult to determine which method is most relevant to solving certain cases.

For the making of the system, it is necessary to pay attention to the interface that is easily understood by the user, but many researchers only emphasize how the method solves the problem, so that the results of the study are not optimal, because only limited to using software, such as excel and others.

In this study the authors conducted a test of several methods in the SPK using Graphic User Interface based applications with MATLAB, this is because it makes it easier in terms of making input data in the form of a matrix. The application that is built consists of a Main Menu in which there is a sub menu file consisting of Form SAW and WP Form.
\end{abstract}

Keywords: SPK, Simple Additive Weighting, Weighted Product, MATLAB

\section{PENDAHULUAN}

Topik Sistem Pendukung Keputusan merupakan yang sangat sering diajukan oleh mahasiswa dalam pengajuan skripsi maupun tugas akhir ataupun bagi dosen yang membuat penelitian, hal ini dikarenakan topik tersebut dapat dipelajari dengan baik, namun sering mengerjakan nya hanya dalam bentuk implementasi, hal ini menyebabkan hasil penelitian kurang maksimal. Ada banyak penelitian yang sifatnya hanya sebatas menerapkan metode untuk menyelesaikan masalah dan ada juga yang menggunakan software sebagai penguji. Pada penelitian sebelumnya menurut Ria Sipahutar(2016) yang berjudul "Fuzzy Multiple Atribute Decicion Macking Untuk Menentukan Kepala Toko Terbaik dengan Menggunakan Metode Technique Order Preference by Similarity To Ideal Solution (TOPSIS)" dan Menurut Nurhasanah (2016) dengan judul "Sistem Pendukung Keputusan Penentuan Penerima Beasiswa menggunakan Metode Simple Additive Weighting (SAW)" hanya sebatas menyelesaikan masalah dengan menguji metode kedalam sofware Matlab melalui Command Window, sehingga menyebabkan hanya yang mengerti perintah command window tersebut yang bisa menggunakan sistem yang dibuat, sementara sistem yang digunakan seharusnya bersifat user friendly, dimana siapa saja dapat memahami dan menggunakan sistem dengan gampang. Untuk membuat sistem haruslah memiliki user interface guna untuk memudahkan pemakai berinteraksi, MATLAB merupakan software yang digunakan untuk mengolah data melalui command window dan M-File dalam bentuk matriks ataupun digunakan untuk pengujian fuzzy, simulasi dan yang lain-lain.

Menurut Tonni Limbong (2015), melakukan pengujian dengan menggunakan MATLAB berbasis GUI, sehingga membantu user dalam melakukan proses pengamanan data teks dengan metode Caesar Chiper ${ }^{[6]}$.

Berdasarkan uraian diatas maka penulis melakukan penelitian dengan judul "Pengujian Sistem Pendukung Keputusan dengan MATLAB"

\section{BAHAN DAN METODE}

Pengujian Sistem Pendukung Keputusan dengan Matlab ini hanya menguji metode Simple Additive Weighting (SAW) dan Metode Weighted Product (WP). Adapun Penjelasan metode sebagai berikut :

\subsection{Metode Simple Additive Weighting (SAW)}


ISSN : 2548-6985

SAW (Simple Additive Weighting) sering juga dikenal dengan istilah metode penjumlahan terbobot. Konsep dasar metode SAW (Simple Additive Weighting) adalah mencari penjumlahan terbobot dan rating kinerja pada setiap alternatif pada semua atribut yang ada. Metode SAW (Simple Additive Weighting) membutuhkan proses normalisasi matriks keputusan $(X)$ ke suatu skala yang dapat diperbandingkan dengan semua rating alternatif yang ada ${ }^{[1]}$.

Metode ini merupakan metode yang paling terkenal dan paling banyank digunakan dalam menghadapi situasi MADM (multiple attribute decision making). Metode ini merupakan suatu metode yang digunakan untuk mencari alternatif optimal dari sejumlah alternatif dengan kriteria tertentu. Membuat matrik keputusan $X$ yang dibentuk dari tabel rating kecocokan dari setiap alternatif pada setiap kriteria. Nilai $X$ setiap alternatif $(\mathrm{Ai})$ pada setiap kriteria (Cj) yang sudah ditentukan, dimana, $i=1,2, \ldots \mathrm{m}$ dan $\mathrm{j}=1,2, \ldots \mathrm{n}$

$$
X=\left\{\begin{array}{ccccc}
X_{11} & x_{12} & \ldots & x_{1 j} \\
\ldots & \ldots & & \cdots \\
X_{i 1} x_{i 2} & \ldots & x_{i j}
\end{array}\right\}
$$

Metode SAW (Simple Additive Weighting) ini mengharuskan pembuat keputusan menentukan bobot bagi setiap atribut. Skor total untuk alternatif diperoleh dengan menjumlahkan seluruh hasil perkalian antara rating (yang dapat dibandingkan dengan lintas atribut) dan bobot tiap atribut. Rating tiap atribut haruslah bebas dimensi dalam arti telah melewati proses normalisasi matriks sebelumnya. Langkah penyelesaian SAW (Simple Additive Weighting) Metode SAW mengenal adanya 2 (dua) atribut yaitu kriteria keuntungan (benefit) dan kriteria biaya (cost). Perbedaan mendasar dari kedua kriteria ini adalah dalam pemilihan kriteria ketika mengambil keputusan ${ }^{[2]}$.

a. Menentukan alternatif, yaitu Ai.

b. Menentukan kriteria-kriteria yang akan dijadikan acuan dalam pengambilan keputusan, yaitu $\mathrm{Ci}$.

c. Menetukan rating kecocokan setiap alternatif pada setiap kriteria.

d. Menentukan bobot preferensi atau tingkat kepentingan (W) setiap kriteria.

$W=\left[W_{1} W_{2} W_{3} \ldots W_{i}\right] \ldots \ldots \ldots(1)$

e. Membuat mariks keputusan berdasarkan kriteria (Ci), kemudian melakukan normalisasi matriks berdasarkan persamaan yang disesuaikan dengan jenis atribut (atribut keuntungan ataupun atribut biaya) sehingga diperoleh matriks ternormalisasi f. Hasil akhir diperoleh dari proses perankingan yatiu penjumlahan dari perkalian matriks normalisasi $\mathrm{R}$ dengan vektor bobot sehingga diperoleh nilai terbesar yang dipilih sebagai alternatif terbaik (Ai) sebagai solusi.

Formula untuk melakukan normalisasi tersebut adalah sebagai berikut :

$$
\left\{\begin{array}{lr}
\frac{x_{i j}}{\max x_{i j}} & \begin{array}{r}
\text { Jika j adalah atribut } \\
\text { keuntungan (benefit) }
\end{array} \\
\frac{\overline{m i n} x_{i j}}{x_{i j}} & \begin{array}{l}
\text { jika j adalah attribute } \\
\text { biaya (cost).............(2) }
\end{array}
\end{array}\right.
$$

Keterangan :

Rij = nilai rating kinerja ternormalisasi.

Xij = baris dan kolom dari matriks

Max $x i j=$ nilai terbesar dari setiap kriteria.

Min $x i j=$ nilai terkecil dari setiap kriteria.

Benefit = nilai terbesaradalah terbaik. Cost $=$ nilai terkecil adalah terbaik.

Nilai preferensi untuk setiap alternatif $(\mathrm{Vi})$ diberikan sebagai berikut:

$$
V_{i}=\sum_{j=1}^{n} w_{j} r_{i j}
$$

Keterangan :

$\mathrm{Vi}=$ rangkaian untuk setipa alternatif.

$\mathrm{Wj}=$ bobot yang telah ditentukan.

$\mathrm{Rij}=$ nilai normalisasi matriks .

Nilai $V_{i}$ lebih besar mengindikasikan bahwa alternatif $A_{i}$ lebih terpilih.

\subsection{Metode Weighted Product (WP)}

Metode WP menggunakan perkalian untuk menghubungkan rating atribut, dimana rating setiap atribut harus dipangkatkan dulu dengan bobot yang bersangkutan. Proses ini sama halnya dengan proses normalisasi. Preferensi untuk alternative Si diberikan sebagai berikut :

$$
\mathrm{S}_{\mathrm{i}}=\prod_{\mathrm{J}=\mathrm{l}}^{\mathrm{n} \mathrm{X}_{\mathrm{ij}}}{ }^{\mathrm{Wj}} \quad ; \text { dengan } \mathrm{i}=1,2,,,,, \mathrm{~m}
$$

Dimana :

$\begin{array}{ll}\mathrm{S} & : \text { Preferensi alternatif dianologikan } \\ & \text { sebagai vektor S } \\ \mathrm{X} & : \text { Nilai kriteria } \\ \mathrm{W} & : \text { Bobot kriteria/subkriteria } \\ \mathrm{I} & : \text { Alternatif } \\ \mathrm{j} & : \text { Kriteria } \\ \mathrm{n} & : \text { Banyaknya kriteria }\end{array}$


ISSN : 2548-6985

dimana $\Sigma \mathrm{Wj}=1 . \mathrm{Wj}$ adalah pangkat bernilai positif untuk atribut keuntungan dan bernilai negatif untuk atribut biaya. Preferensi relatif dari setiap alternatif, diberikan sebagai :

$V_{i}=\frac{\prod_{j=1}^{n} x_{i j}{ }^{w_{j}}}{\prod_{j=1}^{n}\left(X_{j}\right)^{w_{j}}} ; \mathrm{i}=1,2, . ., \mathrm{m} \quad ;$ dengan $\mathrm{i}=1,2, \ldots,, \mathrm{m}$

dimana :

V : Preferensi alternatif dianalogikan sebagai vektor $\mathrm{V}$

$\mathrm{X} \quad$ : Nilai Kriteria

W : Bobot kriteria/subkriteria

i : Alternatif

j : Kriteria

n : Banyaknya kriteria

pada vektor S

:Banyaknya kriteria yang telah dinilai

Langkah - langkah menggunakan metode WP :

1. Mengalikan seluruh atribut bagi sebuah alternatif dengan bobot sebagai pangkat positif untuk atribut manfaat dan bobot berfungsi sebagai pangkat negatif pada atribut biaya.

2. Hasil perkalian dijumlahkan untuk menghasilkan nilai pada setiap alternatif.

3. Mencari nilai alternatif dengan melakukan langkah yang sama seperti langkah satu, hanya saja menggunakan nilai tertinggi untuk setiap atribut tertinggi untuk setiap atribut manfaat dan terendah untuk atribut biaya.

4. Membagi nilai $V$ bagi setiap alternatif dengan nilai standar $\left(V\left(A^{*}\right)\right)$ yang menghasilkan $R$.

5. Ditemukan urutan alternatif terbaik yang akan menjadi keputusan.

\section{HASIL DAN PEMBAHASAN}

Pembahasan dalam penelitian ini saya ambil sampel tentang penentuan guru honor bidang studi, adapun hasil pembahasan nya sebagai berikut :

Dari banyaknya guru honor bidang studi yang melakukan pendaftaran diambil empat guru sebagai contoh untuk penerapan Fuzzy Multiple Attribute Decision Making (FMADM) dalam penyeleksian peserta Guru baru. Data-data dari tiap Guru tersebut di masukan ke dalam Tabel 1 di bawah ini :

Tabel 1 Data Daftar Guru Honor

\begin{tabular}{|c|c|c|c|c|c|}
\hline No & Nama & $\begin{array}{c}\text { Kemam } \\
\text { puan } \\
\text { bidang } \\
\text { studi }\end{array}$ & $\begin{array}{c}\text { Tanggu } \\
\text { ng } \\
\text { jawab }\end{array}$ & $\begin{array}{c}\text { Kreatifit } \\
\text { as }\end{array}$ & $\begin{array}{c}\text { Kreati } \\
\text { fitas }\end{array}$ \\
\hline 1 & $\begin{array}{c}\text { Ramses } \\
\text { Saragih }\end{array}$ & 60 & 75 & 65 & 55 \\
\hline 2 & Katarina & 80 & 60 & 55 & 50 \\
\hline 3 & R.Sihombing & 75 & 65 & 50 & 60 \\
\hline 4 & S.Sembiring & 65 & 70 & 60 & 75 \\
\hline
\end{tabular}

Tabel 2 Bobot

\begin{tabular}{|c|l|c|}
\hline Kriteria & \multicolumn{1}{|c|}{ Keterangan } & Nilai \\
\hline $\mathrm{C}_{1}$ & Sangat Bagus ( SB) & 0,35 \\
\hline $\mathrm{C}_{2}$ & Bagus (B) & 0.25 \\
\hline $\mathrm{C}_{3}$ & Bagus (B) & 0.25 \\
\hline $\mathrm{C}_{4}$ & Kurang Bagus (KB) & 0.15 \\
\hline
\end{tabular}

Setelah diproses melalui tahapan yang sesuai dengan langkah-langkah metode diperoleh hasil sebagai berikut:

Hasilnya :

Nilai terbesar ada pada $\mathrm{V}_{4}$ sehingga alternatif $\mathrm{V}_{4}$ (Guru Honor Bidang Studi ke 4) adalah alternatif yang terpilih sebagai alternatif terbaik. Namun pada kasus ini alternative yang terbaik adalah beberapa Guru yang lulus seleksi secara tepat.Untuk lebih jelas lihat pada tabel 3 dibawah ini.

Tabel 3 Rangking

\begin{tabular}{|l|l|l|}
\hline No & Nama & Total_Nilai \\
\hline 1 & Ramses Saragih & 0,86 \\
\hline 2 & Katarina & 0,85 \\
\hline 3 & R.Sihombing & 0,84 \\
\hline 4 & S.Sembiring & 0,89 \\
\hline
\end{tabular}

Dari tabel 3 diatas yang memiliki nilai terbesar adalah alternatif ke 4 atas nama S.Sembiring.

Dari hasil perhitungan manual metode maka akan diuji dengan aplikasi yang dibuat dengan MATLAB, adapun hasilnya sebagai berikut :

1. Form Menu Utama

Menu Utama merupakan tampilan pertama pada saat aplikasi dijalankan, dimana pada menu ini terdadapt sub menu, yaitu File dan About. Adapun tampilannya dapat dilihat pada Gambar 1 di bawah ini : 


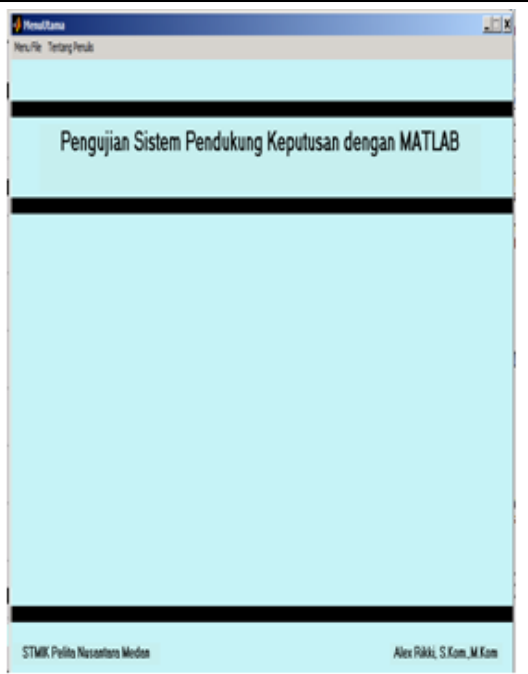

Gambar 1. Menu Utama

\section{Menu File}

Menu file adalah menu yang didalamnya terdapat SAW dan Form WP, adapun tampilannya dapat dilihat pada Gambar 2 di bawah ini :

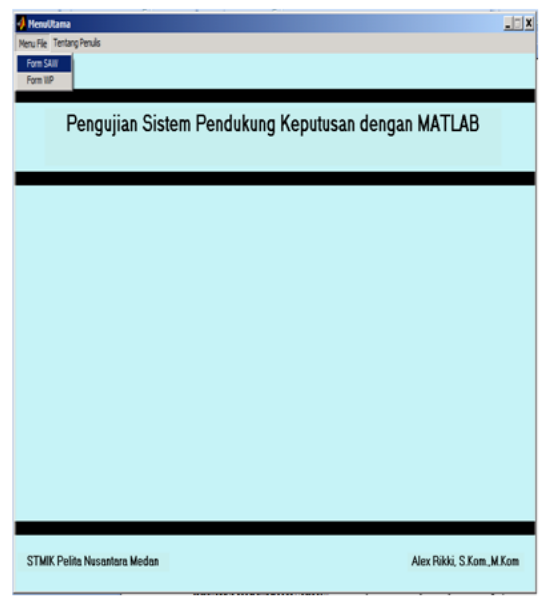

Gambar 2. Menu File

\section{Form SAW}

Form SAW merupakan form untuk proses pengujian, untuk membuka form ini dilakukan dengan mengklik menu file, adapun tampilannya dapat dilihat pada Gambar 3 di bawah ini :

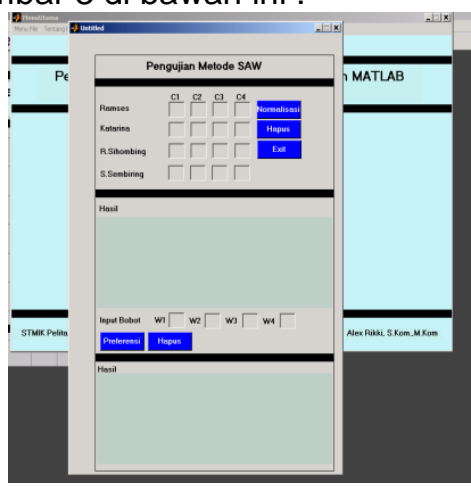

Gambar 3. Form SAW

\section{Form WP}

Form WP merupakan form untuk proses pengujian, untuk membuka form ini dilakukan dengan mengklik menu file, adapun tampilannya dapat dilihat pada Gambar 4 di bawah ini :

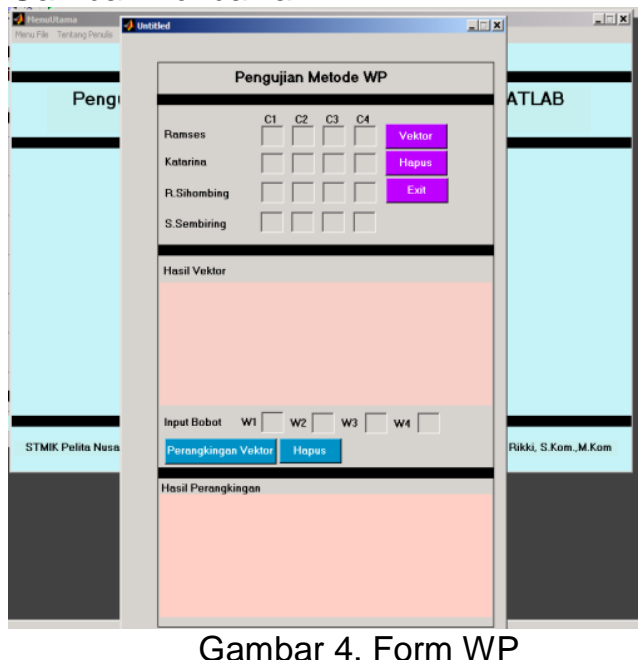

\section{KESIMPULAN}

Berdasarkan hasil pengujian yang sudah dibahas di atas dapat disimpulkan sebagai berikut :

1. Pengujian dengan menggunakan MATLAB sangat mendukung sekali dalam penyelesaian spk, dikarenakan data dalam spk dalam bentuk matriks.

2. Aplikasi menggunakan MATLAB sangat lebih menarik dikarenakan bisa disandingkan dalam bentuk grafik dan simulasi.

3. Rumus dalam metode SAW dan WP dapat langsung diproses dalam coding MATLAB

\section{UCAPAN TERIMAKASIH}

Dalam penelitian ini, penulis banyak mengalami kesulitan-kesulitan, tetapi atas dorongan dari berbagai pihak maka kesulitan tersebut dapat diselesaikan. Untuk itu penulis mengucapkan terimakasih yang sebesarbesarnya kepada Ketua LPPM STMIK Pelita Nusantara, Ketua Program Studi dan temanteman sejawat yang telah banyak membantu dalam menyelesaikan penelitian ini. Secara khusus penulis juga mengucapkan terimakasih kepada Pak Tonni Limbong, S.Kom.,M.Kom yang telah memberikan dorongan untuk selalu berkarya dengan kalimat "Tulis apa yang engkau pikirkan dan Kerjakan apa yang engkau tulis".

Akhir kata penulis berharap semoga tulisan ini dapat bermanfaat bagi orang banyak guna untuk meningkatkan ilmu pengetahuan 
khususnya dibidang Sistem Pendukung

Keputusan.

\section{DAFTAR PUSTAKA}

1. Kusumadewi, Sri.,Hartati, S., Harjoko, A., danWardoyo, R, "Fuzzy Multi Attribute Decision Making (FUZZY MADM)", Penerbit Grahallmu, Yogyakarta, 2006

2. Kusrini, "Konsep dan Aplikasi Sistem Pendukung Keputusan", Penerbit Andi, Yogyakarta, 2007

3. Turban, Efraim dan Jaye Aronson, "Decision Support Systems and Intelligent Systems (Sistem Pendukung Keputusan dan System Cerdas)", Jilid 1. Penerbit Andi, Yogyakarta, 2005

4. Wahana Komputer, "Pengolahan Citra Digital dengan Matlab", PT.Elex Media Komputindo, Jakarta, 2013

5. Kusrini, "Sistem Pendukung Keputusan", Penerbit Andi ,Yogyakarta 2007.

6. Tonni Limbong, "Pengujian Kriptografi Klasik Caesar Chipper Menggunakan Matlab", Prosiding SNITI , USU Press, 2015 